Proceeding of the $1^{\text {st }}$ XCEENG conference, 24-26 March, 1998.

MILITARY TECHNICAJ, COLLEGE.

C.A.IRO-EGYPT

ICEENG $98:$

(1)

FIRST INTERNATIONAL. C(ONH: (1)

ELECTRICAL ENGINEERING

\title{
A FRACTAL-BASED APPROACH FOR RADAR TARGET RECOGNITION
}

\author{
Abdallah M. Elramsisi, and Osama S. Elshehry \\ Air Force Reseach \& Development Center, Air Force Information System Branch
}

Abstract- This paper presents a new approach for classifying radar targets through the fractal analy sis .1 their radar echo. Radar target echo and clutter models have been generated from Rayleigh and Weibut distributior.s. oth targt and clutter signatures have shown fractional Brownian motion behavi(n. Th: radar echo of a target varies basically according to radar target cross section (RCS) and more specificalls according to the size. and geometric shape of the target. Those variations have been efficientil cilpturit and abstracted in terms of average holder constant. Radar target echo and clutter hate also ber: transformed into invariant symmetrized dot patten (SDP) plot, where a correlation coefficient actor. R has been computed. Tha two features, average holder constant and $\mathrm{R}$ have been presented to a multiresolution zeural network to classify seven types of aircraft in the presence of clutter. The multi-iesolutiu? neural net is composed 0 : three sub-nets. each sub-net is a three-layered neural net with a back propuatilu; learning algorithm. Conclusive classification results have been obtained and analyzad in wink confusion matrix format.

Key words: Fractional Brownian motion, radar target echo, clutter, symmetrized dot patletr? it cliteholder constant, radar cross section

\section{I-Introduction}

The main objective of this paper is two folds. the first is to provide a new estimation ol it andul.:... section (RCS) through the Fractal analysis and computation of average holder constum! Alt( ) lin ant

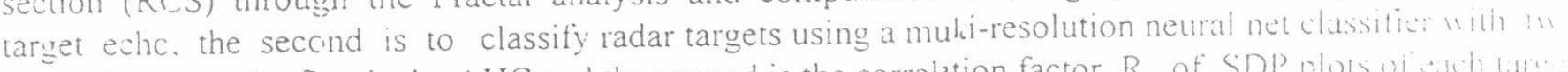
input features, the first is the AHC and the second is the correlation factor. R. of SDP plots al enth tur 1 echo. The important properties of fractal signal models, which enable them to be mudeled su simply..... self similarity and statistical invariance over wide ranges of scales. One of the most uscful muthematici models for the random tractal signal has been the fractal Brownian motion (fBm) of Mandelbot und lin? Ness. It is an extension of the central concept of B-ownian motion that has played an important role in bur: physics and mathematics [1]. A fractal Brownian funcron, $V_{H}(\mathrm{t}), 0<\mathrm{H}<1$. is a single valued functim (1) one variabe, $t$ (usually time). When $\mathrm{H}$ is close to 0 the traces are roughest while as $H$ approaches 1 . Watciare relatively smooth. $H$ relates the typical change in $V, \Delta V=V(12)-V(11)$. To the time difticin: $\Delta t=t 2-t ;$ by the simple scaling law [1]:

$$
\Delta V \propto \Delta t{ }^{H}
$$

whereas the self similar shapes repeat (statistically or exactly) under a magnification. the tBm thucs nupi: statistically only when the $\mathrm{t}$ and $\mathrm{V}$ direction are magnified by different amounts. If 1 is magnilicd h! it factor $\mathrm{r}\left(\mathrm{t}\right.$ becomes $\mathrm{rt}$.). then $\mathrm{V}$ must be magnified by a factor $r^{\prime \prime}(\mathrm{V}$ becomus, " l The variance of variations is proportional to the increment value as [1]:

$$
\sigma^{2}\left(\Delta V^{\prime}\right) \propto(\Delta t)^{2 H}
$$


Proceeding of the $1^{\text {si }}$ ICEENG conference, 24-26 March, 1998.

The variations of a $\left.\mathrm{fBm} V_{H_{1} t_{1}}\right)-V_{H\left(t_{1}-1\right.}$ ) has a Gaussian distribution each with variance [1]:

$$
\sigma^{2}\left(V H\left(t_{i}\right)-V H\left(t_{i}-1\right)\right) \times\left(t_{i}-t_{i}-1\right)^{2 H}
$$

then the standard deviation of the variations can be written as $1 !$ $\sigma\left(V_{H}\left(t_{i}\right)-V_{H}\left(t_{i}-1\right)\right) \propto\left(t_{i}-t_{i}-1\right)^{H}$

this relation is known as $T^{H}$ law where $T^{H}=\left(t_{i}-t_{i}-1\right)^{H}$

The fractal dimension $D$. is a real value greater than the topological dimension E. The relationship butucs D. E. and the roughness measure $\mathrm{H}$ is given by: $\mathrm{D}=\mathrm{E}+1-\mathrm{H}$. For one dimensional . I-L. signal such as noise. $E=1, D=2-H . \quad$ For two dimensiona!. 2-D. signal. $E=2 . D=3-H,[1]$. The fractal dimustim considered scale- rotation-. and translation-invariant. A second fractal feacure is the alerage holf.s. constant (A.HC) which is related to the fractal dimension(D) but is senstive to the scale in previcuth

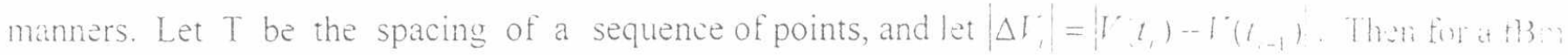
${ }_{H}^{\prime}(t)$, the local holder constant is given by:

$$
a_{i}=\frac{\log \left(\left|\Delta i_{i}\right|\right)}{\log (T)}
$$

The AHC. for a $\mathrm{fBm}$ function $V_{H}(t)$ can be computed from (5; as follows. [2]:

$$
\bar{a}=\arg \left(\alpha_{i}\right)=a \operatorname{cog}\left[\frac{\log \left(\left|\Delta V_{i}^{\prime}\right|\right)}{\log (T)}\right] \text {. }
$$

simmetrized dot pattem (SDP) is one of the most striking and colorful data displaty technipues whi produces figures with the six fold symmeiry. The clue is to corvert data in o a collection ut duts which reflected through mirror planes by a simple computer program. To implement the symmetrized hot partw: starting with a digitized wave, the data is mapped in to a snowflake like pattern oy comparing citch pu: aliacent points, and plotting the result on a polar coordinate graph, and then reflecting the forints throuseh miror plane. SDP plot is also considered to be scale-. rotation-. and shift-insariant. [2]

Radar target is described by an effective area called the radar cross section area. RC $\$$. It is the prifect. area of an equivalent sphere which would return the same echo signal as the tar get. An objut exposed: an electromagnetic wave disperses incident energy in all direction. This distribution of encry in spice is called scattering. and the object itself is often called the scatterer. The energy scattered bas w the sours of the wave. called (back scattering) constitutes the radar echo of the objen. The intensit? of the cuhw is described explicity by the radar cross section (RCS) of the object. The formal detinition of Re $\mathrm{s}$ is ar. b! [3]:

$$
\varepsilon=\lim _{r . l^{2}} 4 \pi r^{2} \frac{\left|E_{s}\right|^{2}}{\left.E_{0}\right|^{2}} .
$$

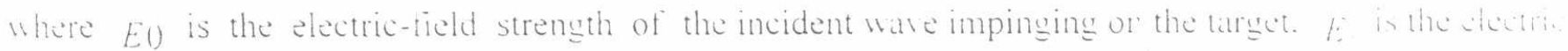
field strength of the scattered wave at the radar, and $\mathrm{r}$ is typically taken to be the range from the ractur wh. target. The dependence of the RCS on $r$, and the need to form the limit. usually disappcars 1 i. +1 From the study and analysis of the radar target echo, it has been found that the reflect sattistical in

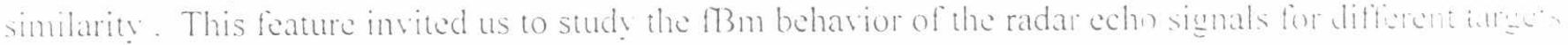


Radar echo signals for different targets (bombers, fighters....) have been simulated as a Rat cilf distribution according to their RCS values. Clutter signals have also been simulated as a $1 !$ eibul distribution $[3,4]$. The $\mathrm{fBn}$ behavior of both radar target echo signals and clutters have beer shown thm the verification of the $T^{4}$ law in one hand and the normal distribution of the variation histogum an other hand [5]. Proposed average values of RCS ${ }^{\circ}$ s, in square meter, for different ty pes of targets are whin in table : , [0]

Table 1 : The Average RCS Of Targets
\begin{tabular}{|l|l|}
\hline Broad Class Of Targets & verage RCS \\
\hline Single engine fighters & 1 \\
\hline Small fighters & 2 to 3 \\
\hline Large fighters & 5 to 6 \\
\hline Small bombers & 10 \\
\hline Med:um bombers & 40 \\
\hline Large bombers & 80 \\
\hline Cargo & $>=100$ \\
\hline
\end{tabular}

\section{2-Radar Echo Generation}

Although there are few cases in which the RCS values are constant. it will generally valy considerathis it each target as the changt: of the aspect angle of the target shape, and the radar frequency. Thise chame.: force us to use statistical methods to describe the radar target [3.4]. In his classical puper (1m im modeling, Peter Swerling established four statistical models for radar targets $|+|$. The Swcrling muict casel is the fluctuating target most trequently used for calculation. It is a description of acollectina many independently moving scatters (Rayleigh amplitude distribution).

\section{2-1 Target Generation}

The radar echo of the target takes the form of Rayleigh distribution in Swerling casel. The Rat fin: probability density (pdt) and the commutative distribution function (cdt) are given by. [3.t]

$$
\begin{aligned}
& f(x)=(1 / x) * \exp [-(x / \bar{x})] . \\
& F(x):=1 \cdots \exp [-(x / \bar{x})]
\end{aligned}
$$

where $x$ is the Rayleigh random variable. $x>0$ and $\bar{x}$ denotes the mean RCS value. A Rat ligh ruth variable can be generaled as follows:

Set $F(x)=U$. Solve for $x$ in terms of $x$. Then $x$ can be written as :

$$
x=-L i n 1-(I) \bar{x}
$$

where $\mathrm{L}$ is a uniform rand om number. Fig. 1 depiets a generated Rayleigh random variahte thr tallget ich with $\mathrm{RCS}=10 \mathrm{~m}^{2}$.

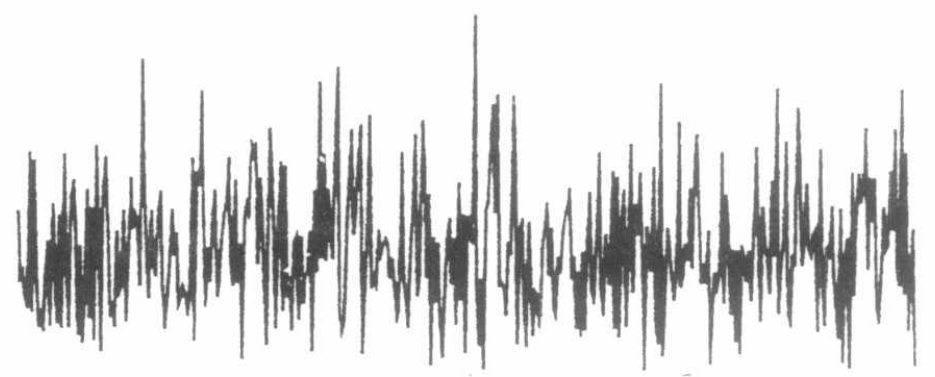

Fig. 1: generated echo for target with $\mathrm{RCS}=10 \mathrm{~m}^{2}$ 
Proceeding of the $1^{\text {st }}$ ICEENG conference, 24-26 March, 1998.

RG.2 386

\section{2-2 Clutter Generation}

According to Swerling - casel. some clutter take the form of Weibul distribution. The pitf and clf uit: II eibul distribution in its general form is given by $[3,4]$ :

$$
\begin{aligned}
& f(x)=\left\{\begin{array}{ll}
b x^{-b} x^{b-1} e^{-(x a)^{4}}, & x>0 \\
0 & x=0
\end{array}\right\} \\
& F(x)=\left[1-\exp (-x / a)^{b}\right]
\end{aligned}
$$

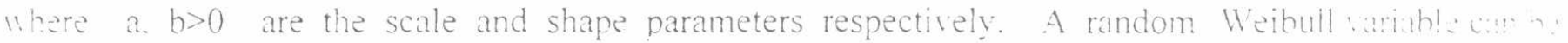
generated as follows :

Set $F(x)=U$, then $x$ can be written as:

$$
x=\left[-\operatorname{Ln}\left(1-U^{i}\right)\right]^{1 / b} a
$$

The pdf and cdf for clutter can be described as:

$$
\begin{aligned}
& f(x)=\left\{\operatorname{Ln}(2) b(x)^{1,-1} \exp \left(-(\ln (2)) x^{\prime \prime}\right\}\right. \\
& F(x)=1-\exp \left(-\operatorname{Ln}(2) x^{\prime \prime}\right) .
\end{aligned}
$$

and the Weibull random variable. $x$ can be written as follows:

$$
x=\left(-\frac{\operatorname{Ln}\left(1-U^{\prime}\right)}{\operatorname{Ln}(2)}\right)(1 / h) .
$$

Fig. I depicts a generated Weibull random variable for clutter with $b=0.3$

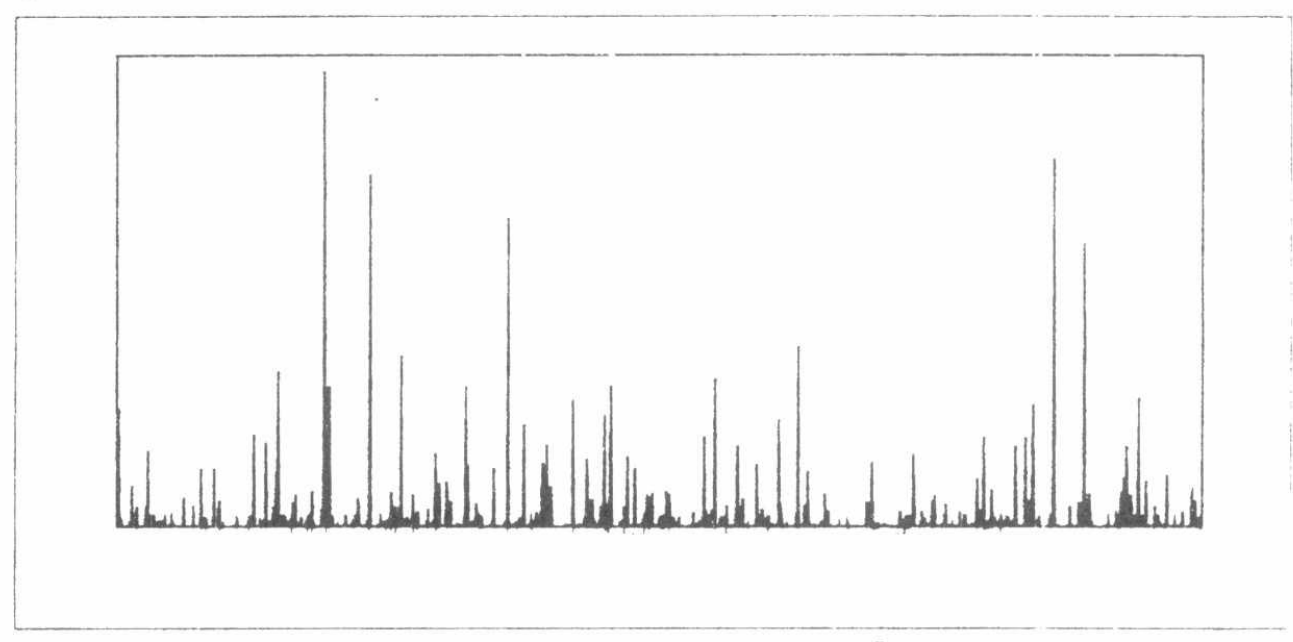

Fig. 2: Generated echo for clutter with $b=0.3$

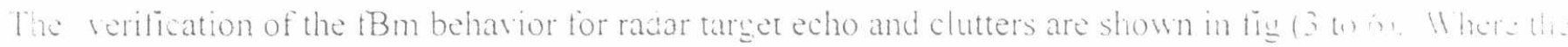
$T$ plots retect linear relation. and the variation histogram depicts Gaussian distribution. 


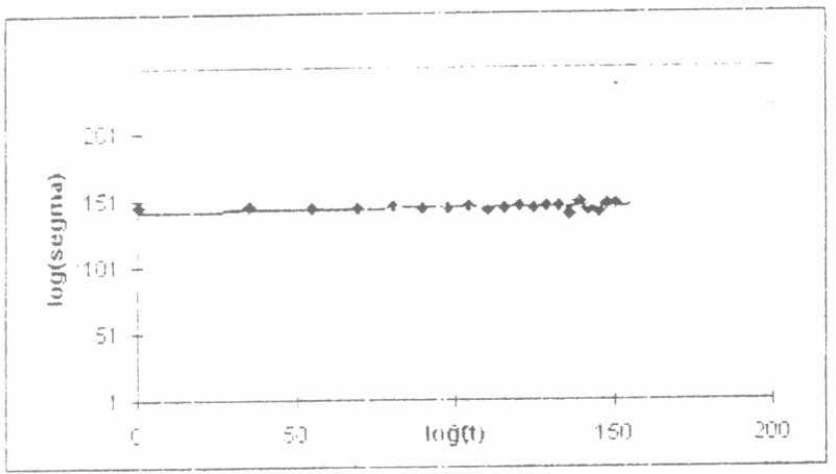

Fig. 3. $T^{H}$ verification for target with RCS $=10$ meter square, RMSE $=0.5$ ()

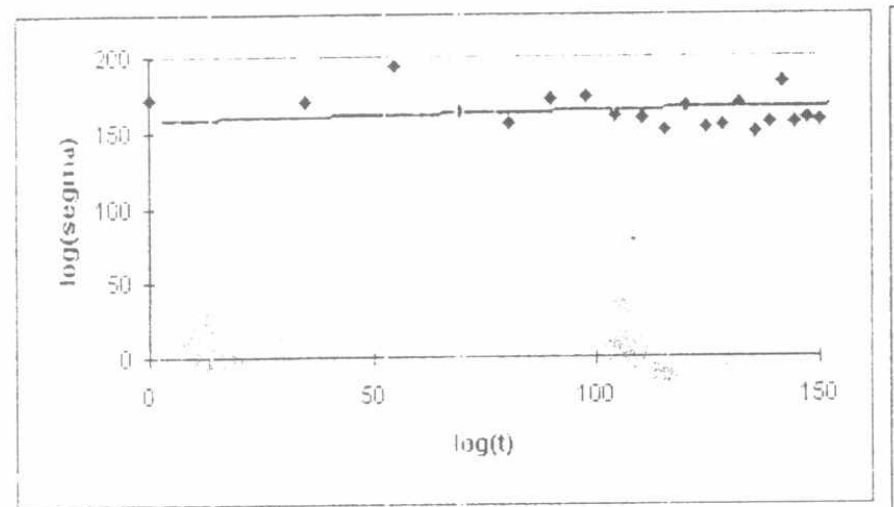

Fig. 5. $T^{H}$ verification for clutter with $b=0.4$, RMSE: $=2.49$.

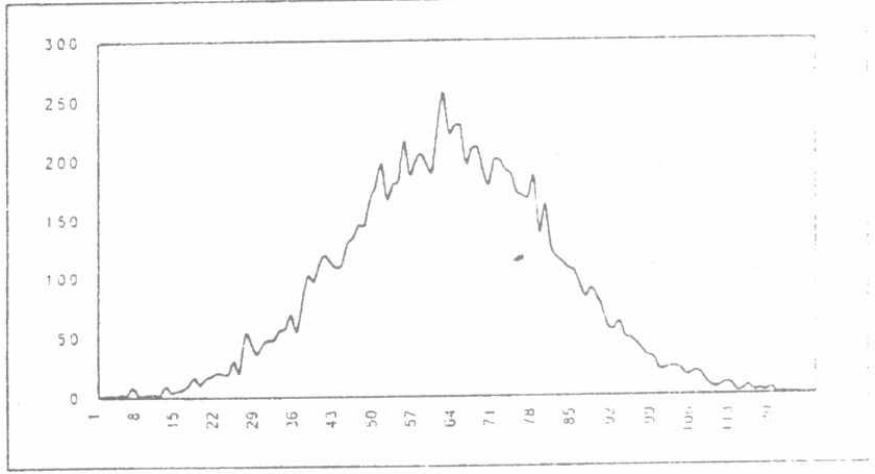

Fig. +. Histogram for target with $R(S=11$.

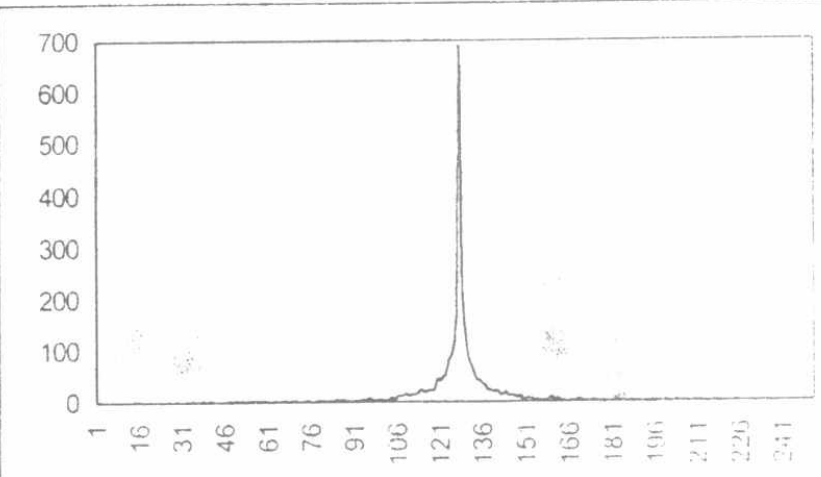

Fig. 6. Histogram verification tirr clutter with $b=() .3$.

\section{3-RCS Estimation}

A main tocus of this research effort is to provide an estimate of radar target cross section through tract.i. analysis of radar echo. The average holder constant of the $\mathrm{fBm}$ traces provides an important infomati.

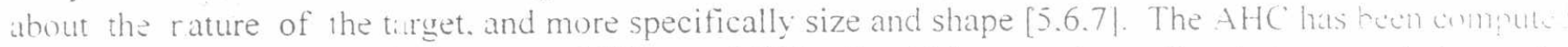

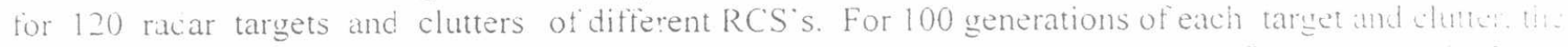
region of the curve contining RCS values of targets of interest has been magnified as shm in $=$ The RCS estimate can be ubstracted in terms of 5 th order polynomial of the following firm

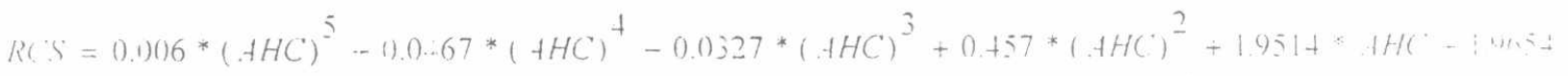

The proposed RCS estimate has been successfully tested and validated over 100 target genclutio: proposed RCS estimation method has achieved $5 \%$ error percentage and 8.26 root mean syme when. between input RCS and estimated one.

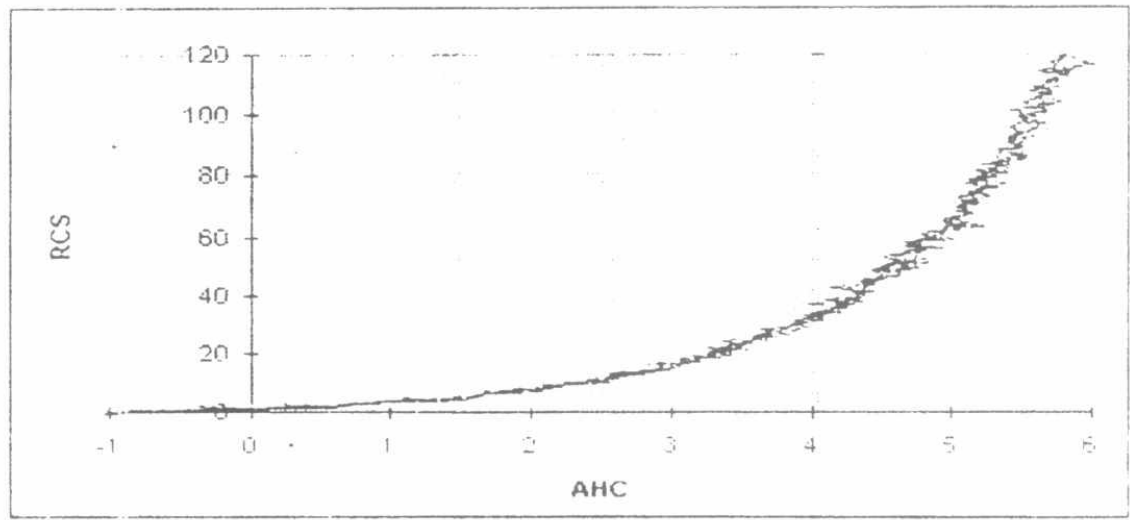

Fis. 7 : The relation between AHC and RCS (multiple running ) 


\section{4 -SDP Plots For Targets And Clutters}

SDP plots for targets of different RCS's and clutters of different b parameter are ploted in Fig is an Fig.9 respectively [2.7]. The SDP patterns have been plotted using $1(.00$ joints for each echo. I comelation coefficient $\mathrm{R}$ for each SDP plot is computed as the number. of displayed points divited h! the total number. of points according to screen resolution. As the correlation anong the points become: huc: $\mathrm{R}$ values become higher and vice versa. SDP patterns provide a qualitative ard quantitativ measures tiryet types in tems of SDP plot display, and the correlation coefficient. $R$ It can be noticed that ilutio:

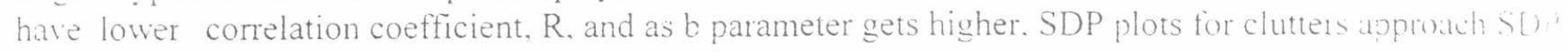
plots for target.

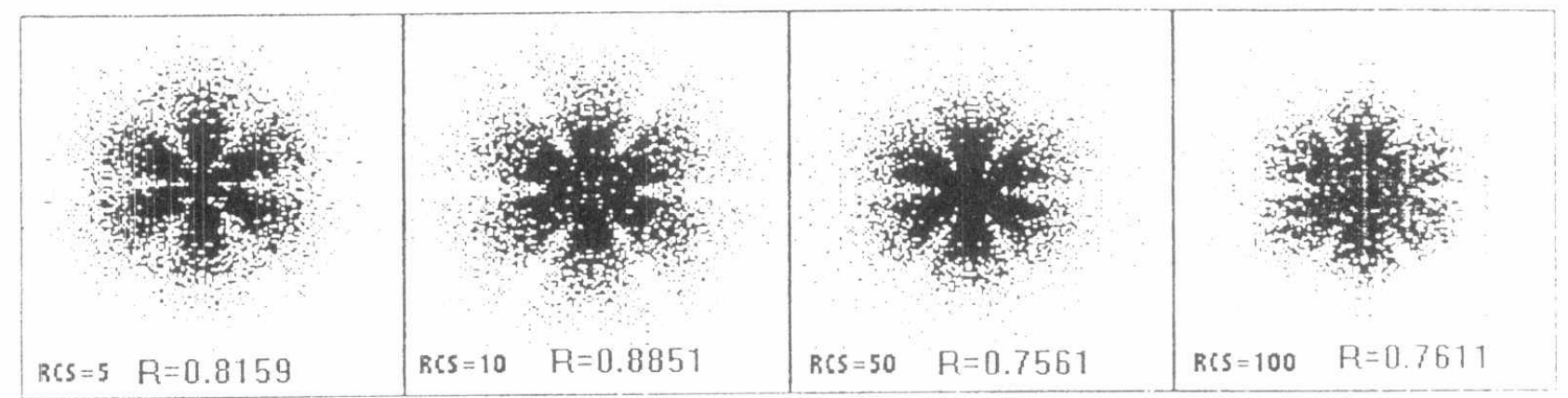

Fig. 8: SDP piots for targets with different RCs

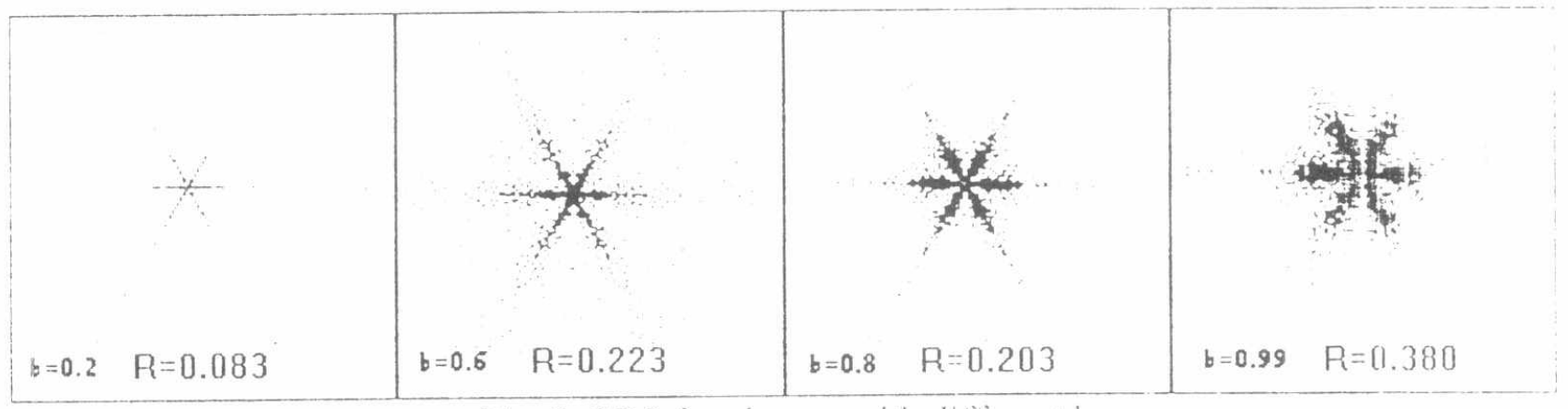

Fig. 9: SDP for clutters with different b

\section{5-. Veural Net Classifier.}

The block diagram of the proposed multi-resolution neural net classification scheme is shom in in in. I The first layer, the general class subnet. ciassifies input samples to four major classes: airge. humber fighters. and background clutter. The second layer consists of two neural sut-nets. The tirst one is uscet if : classifying specitic tighter types (large fighters as F-15, middle tighter as $1-16$, small tighter as . Yig 21 . The second subnet is used for classifying specific bomber types(targe bomber. middle be me: bomber). Each subnet (bomber. fighter) is activated by an enable inpu: from the generul cliss whin where the two input features (AHC. R) are avaitable as imput for the activated neural subnel. Hig. 11 at. c) depicts the three neural subnet architectures. Each subnet is composed of hrec havers. ar dahols a hin propagation learning algorithm [8]. Fig.12 depicts graphical representation of the feature space. Where the back ground clutter class occupies the bottom area, and the other seven classes of targets mal! tighte. midile fighter, large fighter. small bomber, middle bomber, large bomber, and cargo occup! the uppet are. of the graph from left to right respectively. 


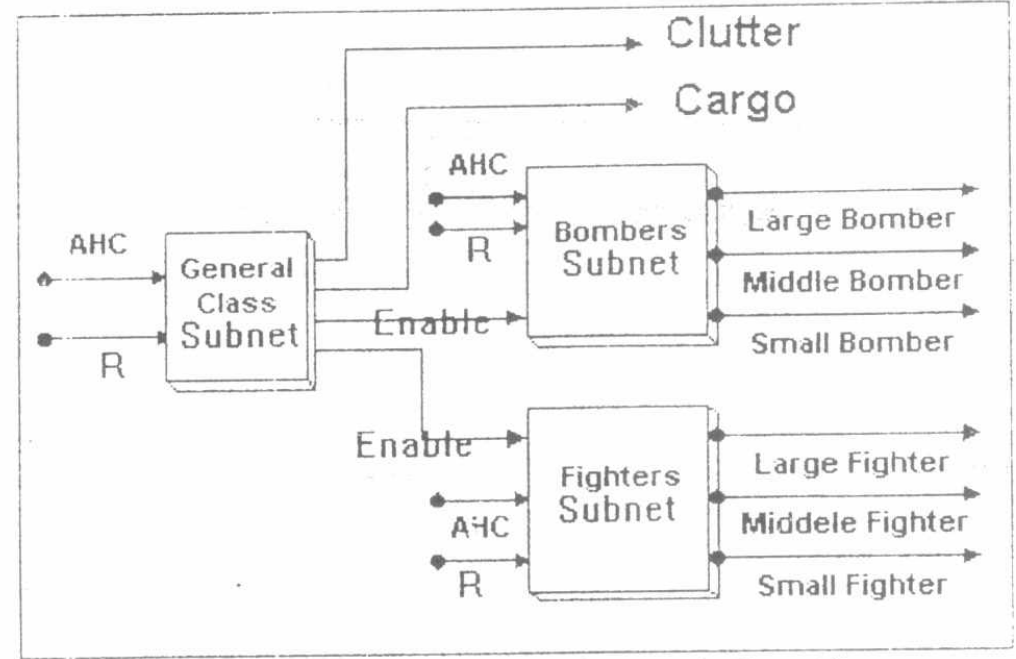

Fig. 10: Block diagram of Neural Classifier
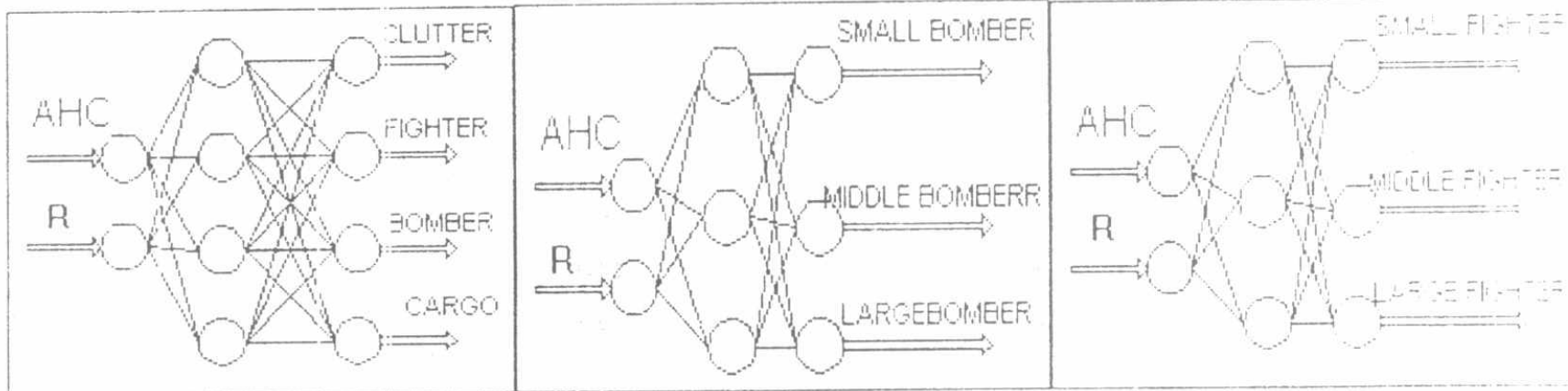

!ig. 11.a. General Class Subnet Fig.11.b Bombers Subnet

Fig. 11.c. Fighters lunne

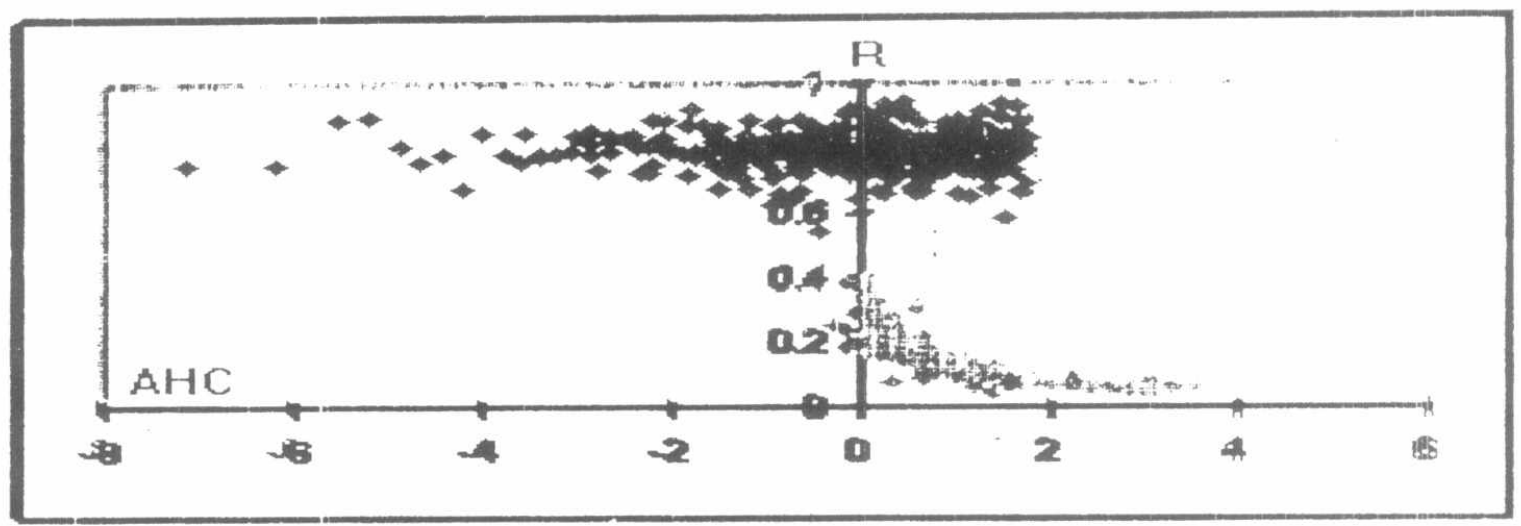

Fig. 12. Graphical Representation Of Feature Space

The perfo:mance of the proposed multi-resolution classification scheme has been tested aml and . Test results are summarized in the confusion matrix shown in table t. where samples of cach cl. been presented to the clas:ifier 100 times [7]. The average value of the percentage of correct recingum an $88^{\circ} \%$. The recognition race for each class is computed as the number of times the chasilie:. wit: specitic class with resfect o the 100 presentations. For example. the classifier outputs lares tigh a 131 times. 
Proceeding of the $1^{\text {st }}$ ICEENG conference, 24-26 March, 1998.

Tablet: Confusion matrix of the classifier

\begin{tabular}{|c|c|c|c|c|c|c|c|c|c|}
\hline & \begin{tabular}{|l|} 
Small \\
Fighter
\end{tabular} & \begin{tabular}{|l|} 
Middle \\
Fighter
\end{tabular} & $\begin{array}{l}\text { Large } \\
\text { Fighter }\end{array}$ & $\begin{array}{l}\text { Small } \\
\text { Bomber }\end{array}$ & $\begin{array}{l}\text { Middle } \\
\text { Bomber }\end{array}$ & $\begin{array}{l}\text { Large } \\
\text { Bomber }\end{array}$ & C: $r g o$ & Clutter & $\begin{array}{l}\text { Recognition } \\
\text { Rate }\end{array}$ \\
\hline Small Fighter & 81 & & & & & & & & 081 \\
\hline Middle Fighter & 18 & 68 & & & & & & & 086 \\
\hline Large Fighter & & 31 & 100 & & & & & & 1.3 \\
\hline Small Bomber & & & & 89 & & & & & 0.83 \\
\hline Middle Bomber & & & & 11 & 68 & & & & 0.79 \\
\hline Large Bomber & & & & & 32 & 100 & & & $1.3 \%$ \\
\hline Cargo & & & & & & & 160 & & 1 \\
\hline Clutter & & & & & & & & $100 \%$ & 1 \\
\hline unclassified & 1 & 1 & & & & & & & 0.02 . \\
\hline $\begin{array}{l}\text { Correct } \\
\text { Recognition \% }\end{array}$ & $81 \%$ & $68 \%$ & $100 \%$ & $89 \%$ & $68 \%$ & $100 \%$ & $10 \%$ & $100 \%$ & \\
\hline
\end{tabular}

\section{Conclusion}

The proposed approach presents a new reliable method for radar target classification based on the trat. estimation of the radar cross section. The average holder constant for each signal has been wed to pris hi. an estimate for target RCS. The correlation factor. R. of SDP plots along with RCS estimates for turget and clutters have been used to classify samples from eight target classe;. T he proposed schume cim? h. used in a wide spectrum of military applications, especially reconnassance and earls waming ants. s! stems.

\section{References}

[1] M. F. Barnsely. R. L. Devaey." The Science Of Fractal Images," Sprins-lerlure l1. Iys

(2) Clifford A. Pickover. "Computers. Pattern. Chaos and Beauty. "ST. Martin's Press. M. 1 (4)

(3) Sholnik MI.," Introduction To Radar System," HeGraw-Hill. 1980).

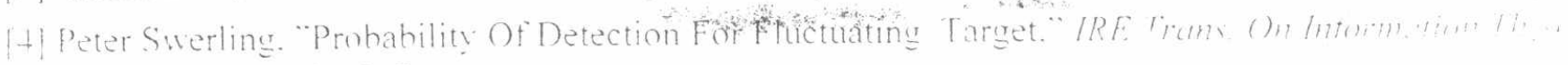
April 1960 . pp. 296-31)

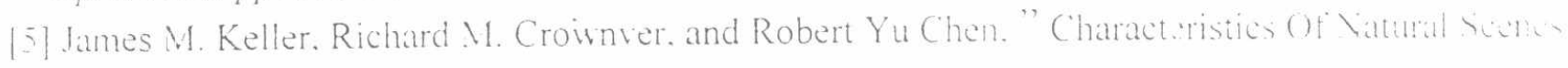

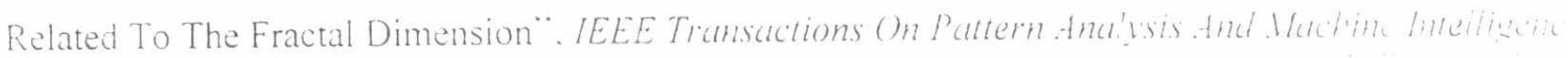
I'ol P. AII-9. Vo 5. September 198-.

[6] Stuart M. Lee. editor. "Stealth Low Observable Composite Aircrati". In emational Enc chpedian... Composites, Vol. 6. pp. +04-.20. VCH. NY.

[7] A. M. Elramsisi, I. A. Ismail. B. Ahmed Baz." On The Classification Ot partially-ocefuced Fractal Images." Proceeding of the fourth International Conference on Artificial Intelligence tiplicurom. IC.11.4.pp. 137-150. ('uiro. Egypt. Jan 16-19.1996.

$[8]$ R. Lippman. "An Introduction To Computing With Neural Nets". IEEL. ASSP Ifugurinc. MP - . 2?

$$
\text { 1pril io, }
$$

